\title{
Interelasi Masyarakat Adat Kajang dan Pola Kehidupan Modern
}

\author{
Askar Nur \\ askarr.nur@gmail.com \\ Bahasa dan Sastra Inggris, Fakultas Adab dan Humaniora, Universitas Islam Negeri Alauddin \\ Makassar
}

\begin{abstract}
Abstrak
Penelitian ini menganalisa tentang interelasi masyarakat adat Kajang dengan kehidupan modern dan menelaah korelasi dunia kesehatan modern dengan budaya masyarakat adat Kajang yang tidak menggunakan alas kaki dalam kehidupan sehari-hari. Hipotesis penelitian ini menunjukkan bahwa kehidupan modern dengan pola kehidupan masyarakat adat Kajang tanpa alas kaki memiliki kontradiksi. Di sisi lain dunia kesehatan modern menghendaki penggunaan alas kaki sebagai bentuk antisipasi dari pelbagai penyakit akan tetapi adat Kajang melalui fatwa adat Pasang ri' Kajang menginstruksikan agar masyarakat adat menjaga jarak dari ihwal yang mengandung unsur modern termasuk penggunaan alas kaki. Pendekatan penelitian ini adalah pendekatan kualitatif deskriptif yang menggunakan teori sosiologi budaya Pierre Bourdieu dan menggunakan metode etnografi. Tujuan penelitian ini adalah mengungkapkan interelasi masyarakat adat Kajang dengan budaya tanpa alas kaki dan dunia kesehatan modern.
\end{abstract}

Kata Kunci: Adat Kajang, Budaya Modern, Etnografi

\section{Pendahuluan}

Ruang kebudayaan merupakan perkara ultim dalam kehidupan manusia. Kebudayaan dan manusia memiliki interaksi dan menjadi pondasi atau dasar segala yang bersangkutan dengan proses hidup manusia. Manusia yang menciptakan kebudayaan namun kemudian kebudayaan yang membentuk manusia (Maran, 2007).Hal demikian didukung pula oleh kemajuan kehidupan manusia saat ini yang identik dengan perkembangan teknologi dan gaya serta pola hidup modern sehingga corak budaya tradisional lambat laun mengalami proses degradasi.

Kendati demikian, di tengah arus globalisasi masih terdapat beberapa kelompok atau lembaga masyarakat khususnya komunitas-komunitas adat di suatu wilayah yang masih mempertahankan kebudayaan lamanya dari generasi ke generasi. Salah satu komunitas adat yang masih bertahan sampai pada era modernisasi seperti saat ini yakni komunitas atau suku adat Ammatoa Kajang di Kabupaten Bulukumba, Sulawesi Selatan. 
Masyarakat adat Ammatoa Kajang atau sering disebut "To Kajang” yang artinya orang Kajang merupakan kelompok masyarakat yang masih menjaga dan merawat pesan filosofi nenek moyang mereka yang tertuang dalam "Pasang ri' Kajang" untuk selalu hidup dengan nilai kebudayaan yang dianut dan menjaga diri dari intervensi kehidupan luar seperti pola kehidupan budaya populer sebagai hasil produksi dari arena modernisasi.

Pasang merupakan sistem pengetahuan tradisional masyarakat ammatoa yang ajarannya dipercaya bersumber dari Turie* A'rana (Tuhan) yang telah diwariskan secara turun temurun sejak generasi ammatoa I (Too Mariolo) dan wajib diamalkan oleh setiap warga masyarakat. Ammatoa sebagai falsafah hidup untuk kemudian diwariskan. secara lisan kepada generasi berikutnya. Lambang ketaatan terhadap isi Pasang diwujudkan dalam kesederhanaan hidup yang dalam istilah setempat disebut pola hidup "Kamase-masea". Hidup sederhana dan pasrah pada kesederhanaan merupakan hakekat dan inti dari Pasang (Disnawati, 2013).

Salah satu tata nilai yang termuat dalam Pasang adalah prinsip dalam berpenampilan, misalnya keharusan bagi seluruh masyarakat adat maupun para pengunjung kawasan adat untuk mengenakan pakaian berwarna hitam yang konon sebagai simbol kesetaraan dan tidak menggunakan alas kaki sebagai penanda bahwa tidak ada jarak antara manusia dengan alam sehingga keduanya mampu saling berinteraksi dan juga sebagai bentuk maklumat bahwasanya masyarakat adat Kajang tidak menghendaki intervensi dari luar (kehidupan modern).

Senada dengan itu, Judi Bary dalam "Ekologi Revolusioner" menamai kedekatan manusia dengan alam sebagai fenomena Biosentris atau ekologi dalam, yakni alam tercipta bukan untuk melayani manusia lebih dari itu ia hadir dan bersama dengan manusia. Kendati demikian, terhadap apa yang diistilahkan Bary memiliki keterkaitan dengan prinsip budaya masyarakat Adat Kajang yang terelaborasi dalam nilai kesederhanaan (kamase-masea) dan turut mendukung atensi dan empati masyarakat terhadap alam.

Kesederhanaan sebagai pola utama kehidupan merupakan perkara yang terbilang sangat jarang digeluti manusia pada model kehidupan saat ini. Seperti kita ketahui bersama bahwa zaman yang kita hadapi dewasa ini merupakan zaman yang bergerak ke depan (modernisasi). Perkembangan teknologi dan perubahan gaya hidup masyarakat merupakan ciri mendasar dari proses modernisasi. Modernisme sebagai proses kemunculan industrialisme, kapitalisme dan pengawasan yang mengacu kepada bentuk-bentuk kultural manusia yang terikat dengan modernisasi.

\section{Pembahasan}

Proses modernisasi tentu meniscayakan terjadinya perubahan sosial dan kebudayaan masyarakat baik dari segi ekonomi, pembangunan hingga kesehatan. Pada dunia kesehatan modern khususnya, proses perkembangannya sangat dipengaruhi oleh kemajuan teknologi. Hal demikian tergambar melalui seperangkat alat kesehatan canggih yang berbasiskan teknologi dan tak hanya itu, kesehatan modern pun mendemonstrasikan cara hidup sehat bagi masyarakat. 
Seperti anjuran untuk memakai alas kaki (sandal dan sepatu) agar terhindar dari pelbagai penyakit.

Anjuran tersebut tentu menuai kontroversi dan polemik bagi masyarakat khususnya adat Kajang yang memiliki kebiasaan tersendiri untuk tidak menggunakan alas kaki. Interelasi adat atau budaya Kajang dengan kesehatan modern sampai titik ini tampak kontradiktif.

Dalam pandangan sosiologi budaya, masyarakat dan kebudayaan dalam perkembangannya tidak menutup kemungkinan suatu kebudayaan yang ada dalam suatu masyarakat akan mengalami perubahan ataupun reproduksi budaya (Ritzer, 2012). Dalam proses perubahan dan reproduksi budaya tidak terlepas dari adanya berbagai faktor yang mempengaruhinya. Adanya perubahan dan reproduksi budaya dalam suatu masyarakat akan berpengaruh juga terhadap perubahan kehidupan sosial dan budaya masyarakat yang terkait.

Seperti halnya budaya masyarakat adat Kajang dan kesehatan modern yang keduanya membangun pola interelasi kontradiktif. Bourdieu dalam sosiologi budayanya yang menganalisis produksi dan reproduksi budaya dan menggunakan konsep tentang habitus dan arena serta hubungan dialektis antara keduanya, maka akan ditemukan proses interelasi antara masyarakat adat Kajang dan kesehatan modern berikut faktor yang mempengaruhi hadirnya ruang kontradiktif antara keduanya.

\section{Budaya Lokal dan Budaya Modern}

Beberapa jurnal penelitian dan artikel ilmiah lainnya menjadikan budaya lokal sebagai objek kajian namun sebahagian hanya berhenti pada gambaran kebudayaan lokal dan hanya sedikit yang membahas tentang tantangan budaya lokal di tengah arus modernisasi serta solusi demi keberlangsungan budaya lokal.

Pada dasarnya, corak kehidupan modern memiliki dua makna, meminjam sekaligus mengafirmasi perkataan Nurcholish Majid tentang modernisasi yang di satu sisi bermakna gaya hidup modern lebih kepada westernisasi. Sementara, di sisi lain bermakna sikap modern yang lebih kepada cara berpikir dinamis.

Prinsip Kamase-mase' dalam budaya masyarakat adat Kajang terejawantahkan dalam bentuk sikap hidup bergelimang kesederhanaan dan lebih menjurus kepada penolakan terdapap budaya modernisasi yang kebarat-baratan. Akan tetapi tetap bercorak modernisasi sebagai bentuk sikap berpikir yang dinamis. Salah satu contohnya adalah masyarakat adat Kajang masih tetap membuka diri terhadap masyarakat luar tanah adat yang sering mengunjungi kawasan tanah adat. Hal demikian menunjukkan bahwa masyarakat adat Kajang tetap menjunjung tinggi kekerabatan antar manusia.

\section{Kesimpulan}


Mempertahankan nilai-nilai budaya dan pola perilaku merupakan bentuk pelestarian budaya lokal yang sampai saat ini tak hentinya mendapat tekanan dan gangguan dari dunia luar. Tak dapat dipungkiri bahwa perkembangan budaya modern dan globalisasi yang dikemas dalam berbagai bentuk media komunikasi dan informasi juga turut mempengaruhi turunnya apresiasi masyarakat terhadap eksistensi kebudayaan. Adanya proses urbanisasi dengan hadirnya masyarakat pendatang juga mengakibatkan hilangnya rasa kepemilikan terhadap nilai-nilai budaya yang dimiliki daerah tersebut, para pendatang tersebut lebih bangga terhadap nilai-nilai budaya darimana mereka berasal dan berupaya untuk mengembangkan budayanya pada tempat yang didatanginya sehingga lambat laun kebudayaan pendatang tersebut kemungkinan bisa dapat lebih berkembang dibandingkan kebudayaan asli daerah setempat.

Tak hanya masyarakat adat Kajang yang sampai hari ini mampu mempertahankan nilainilai budaya, beberapa masyarakat adat lainnya di Sulawesi Selatan juga melakukan hal yang sama namun tak banyak yang mampu bertahan di atas gempuran kebudayaan modern. Oleh karenanya, Kesadaran diri para generasi muda tentu menjadi syarat utama pelestarian budaya lokal di masa sekarang.

\section{Daftar Pustaka}

Maran, Rafael Raga (2007), Pengantar Sosiologi Politik; Jakarta Rineka Cipta/ http://kin.perpusnas.go.id/DisplayData.aspx?pId=93728\&pRegionCode=UNTAR\&pClie $\underline{\text { ntId }=650}$

Disnawati, D. Penerapan Prinsip Hidup Kamase-masea Masyarakat Adat Ammatoa Kajang, Bulukumba Sulawesi Selatan dalam Pengelolaan Sumber Daya Alam. Sabda: Jurnal Kajian Kebudayaan, 8(1), 83-90.

Ritzer, G., \& Yagatich, W. (2012). Contemporary sociological theory. The Wiley-Blackwell Companion to Sociology. Oxford: Wiley-Blackwell, 98-118.

El Maries, J. (2017). Tarètan Sebagai Reproduksi Budaya Masyarakat Madura (Studi Etnografi pada Masyarakat Madura Perantau) (Doctoral dissertation, Universitas Brawijaya).

Szeman, I., Brown, N., Beasley-Murray, J., Bourdieu, P., Betensky, C., Ekelund, B. G., ... \& Pizanias, C. (2000). Pierre Bourdieu: fieldwork in culture. Rowman \& Littlefield. 